\title{
ESTUDO DA DISSOLUÇÃO DE PRECIPITADOS DURANTE O REAQUECIMENTO DE PLACAS DE AÇOS MICROLIGADOS: UMA AVALIAÇÃO QUANTITATIVA*
}

\author{
Cynthia Serra Batista Castro ${ }^{1}$ \\ Diana Pérez Escobar ${ }^{1}$ \\ Fábio Dian Murari \\ Ronaldo Antônio Neves Marques Barbosa ${ }^{3}$ \\ Margareth Spangler Andrade ${ }^{4}$
}

\section{Resumo}

A dissolução de precipitados complexos de $\mathrm{Ti}$ e $\mathrm{Nb}$ durante a etapa de reaquecimento de placas foi estudada utilizando-se amostras de quatro aços microligados. As análises foram realizadas por microscopia óptica e por microscopia eletrônica de varredura nas amostras de placas antes e após reaquecimento em diferentes tempos de encharque. Os resultados mostraram que os precipitados com tamanho inferior a $100 \mathrm{~nm}$ foram dissolvidos durante a etapa de reaquecimento do material, não necessitando de encharque. Para precipitados de $100 \mathrm{~nm}$ até $500 \mathrm{~nm}$, verificou-se dissolução parcial com o aumento do tempo de encharque até 50 min. Para precipitados mais grosseiros, não houve dissolução significativa durante as etapas de encharque estudadas. Os resultados foram influenciados pelo grau de limpidez dos aços, nível de segregação e razão Ti/N.

Palavras-chave: Dissolução de precipitados; Aços microligados; Precipitação de $(\mathrm{Nb}, \mathrm{Ti})(\mathrm{C}, \mathrm{N})$.

\section{STUDY OF THE PRECIPITATES DISSOLUTION DURING THE SLAB REHEATING OF MICROALLOYED STEELS}

\section{Abstract}

The dissolution of complex $\mathrm{Ti}$ and $\mathrm{Nb}$ precipitates during the slab reheating of four microalloyed steels was studied. The analyses were performed by means of optical microscopy and scanning electron microscopy using as-cast samples, as well as after reheated and treated with different soaking times. The results showed that the precipitates smaller than $100 \mathrm{~nm}$ were dissolved during the reheating step and that no additional soaking time was required. Precipitates with diameter between $100 \mathrm{~nm}$ and $500 \mathrm{~nm}$ were partially dissolved after $50 \mathrm{~min}$ of soaking time. For the coarser precipitates (>500 nm), no significant dissolution was verified during the soaking steps evaluated. The results were influenced by the steel cleanliness, segregation level and $\mathrm{Ti} / \mathrm{N}$ ratio.

Keywords: Precipitates dissolution; Microalloyed steels; (Nb,Ti)(C,N) Precipitation.

1 Engenheira Metalurgista, D. Sc., Pesquisadora em Ciência e Tecnologia do Instituto Senai de Inovação em Metalurgia e Ligas Especiais, Centro de Inovação e Tecnologia SENAI FIEMG Campus CETEC, Belo Horizonte, MG, Brasil.

2 Engenheiro Metalurgista, D. Sc., Pesquisador Especialista, Centro de Pesquisa da Usiminas, Ipatinga, MG, Brasil.

3 Engenheiro Mecânico, PhD., Professor Titular do Departamento de Engenharia Metalúrgica e de Materiais da Universidade Federal de Minas Gerais, Belo Horizonte, MG, Brasil.

4 Física, D. Sc., Diretora do Instituto Senai de Inovação em Metalurgia e Ligas Especiais, Centro de Inovação e Tecnologia SENAI FIEMG - Campus CETEC, Belo Horizonte, MG, Brasil. 


\section{INTRODUÇÃO}

A utilização de elementos chamados microligantes, como o $\mathrm{Ti}$, $\mathrm{Nb}$ e $\mathrm{V}$, combinada com o processamento por laminação controlada, é usada para promover refino de grão e obter aços que combinam elevada resistência mecânica e tenacidade. $O$ processo de laminação controlada é caracterizado pela deformação da austenita, na laminação de acabamento, em uma faixa de temperatura tal que não ocorra seu amaciamento por recristalização. Nesta faixa de temperatura, o fenômeno de recristalização da austenita é suprimido pelo fenômeno de precipitação de $\mathrm{Nb}$, uma vez que são concorrentes. Além disso, os precipitados de $\mathrm{Nb}$, finos e dispersos, ancoram o grão de austenita, impedindo o seu crescimento [1]. A austenita encruada se caracteriza pela elevada densidade de sítios para nucleação da fase ferrita. Como resultado, obtêm-se aços com reduzido tamanho de grão ferrítico final. Além do efeito refinador de grão, o $\mathrm{Nb}$ também contribui com o aumento da resistência pelo mecanismo de endurecimento por precipitação.

Além de elevar a temperatura para que o material possa ser conformado, o reaquecimento de placas que antecede a laminação a quente possui como finalidade dissolver os precipitados ricos em $\mathrm{Nb}$, formados durante a solidificação do aço, até que o teor deste elemento em solução sólida atinja níveis que favoreçam ao máximo a sua precipitação durante a laminação e/ou resfriamento da chapa. A presença de precipitados ricos em $\mathrm{Ti}$, parcialmente dissolvidos ou não, é utilizada para inibir o crescimento excessivo do grão austenítico durante o período de encharque [2].

O tempo e a temperatura de dissolução desses precipitados irão depender do seu tamanho inicial, distribuição e densidade, além do teor de outros elementos presentes na liga [3].

No presente trabalho, avaliou-se o efeito do tempo de encharque durante a etapa de reaquecimento de placas na dissolução de precipitados ricos em $\mathrm{Nb}$ e Ti para quatro aços microligados. Esses aços foram caracterizados por meio de microscopias óptica e eletrônica de varredura no estado lingotado e após as etapas de reaquecimento e encharque.

\section{MATERIAIS E MÉTODOS}

Foram utilizadas amostras de placas de aços microligados ao $\mathrm{Nb}$ e Ti, cujos teores de $\mathrm{C}, \mathrm{Nb}, \mathrm{Ti}$ e $\mathrm{N}$ são mostrados na Tabela 1. Os aços $\mathrm{A}, \mathrm{C}$ e D apresentaram razão $\mathrm{Ti} / \mathrm{N}$ acima da estequiométrica $(3,42)$, enquanto o aço $\mathrm{B}$ apresentou relação abaixo desse valor.

Tabela 1. Composição química dos aços estudados (\%p/p)

\begin{tabular}{cccccc}
\hline Aço & $\mathbf{C}$ & $\mathbf{N b}$ & $\mathbf{T i}$ & $\mathbf{N}$ & $\mathbf{T i} / \mathbf{N}$ \\
\hline $\mathbf{A}$ & 0,087 & 0,019 & 0,024 & 0,0035 & 6,9 \\
B & 0,038 & 0,032 & 0,006 & 0,0026 & 2,3 \\
C & 0,074 & 0,046 & 0,016 & 0,0038 & 4,2 \\
D & 0,180 & 0,036 & 0,027 & 0,0033 & 8,2 \\
\hline
\end{tabular}

A caracterização dos precipitados foi realizada por microscopias óptica e eletrônica de varredura (MEV). As seções analisadas foram lixadas e depois polidas com pasta de diamante com granulometria de até $1 \mu \mathrm{m}$. Em seguida, foram atacadas com 
reativo nital $2 \%$. As análises foram feitas em seções paralelas à direção de lingotamento, antes e após os tratamentos térmicos.

Os tratamentos térmicos, realizados em um forno de resistência elétrica e atmosfera não controlada, consistiram no reaquecimento de subamostras com largura entre $80 \mathrm{~mm}$ e $100 \mathrm{~mm}$, cerca de $120 \mathrm{~mm}$ de comprimento e $30 \mathrm{~mm}$ de espessura, retiradas a $1 / 4$ e centro da espessura das placas, até as temperaturas de encharque ( $T_{E N C H}$ ), obtidas para cada aço pelo software ThermoCalc, mostradas na Tabela 2. As subamostras atingiram as temperaturas desejadas após 250 min de permanência no forno. Alcançada a temperatura de encharque, permaneceram no forno por 0 min e 50 min e, em seguida, foram temperadas em água a temperatura ambiente, para preservação do estado de dissolução dos precipitados, Figura 1.

Tabela 2. Temperaturas de encharque utilizadas nos tratamentos dos aços

\begin{tabular}{cc}
\hline Aço & $\mathrm{T}\left({ }^{\circ} \mathrm{C}\right)$ \\
\hline $\mathrm{A}$ & 1150 \\
$\mathrm{~B}$ & 1150 \\
$\mathrm{C}$ & 1180 \\
$\mathrm{D}$ & 1220 \\
\hline
\end{tabular}

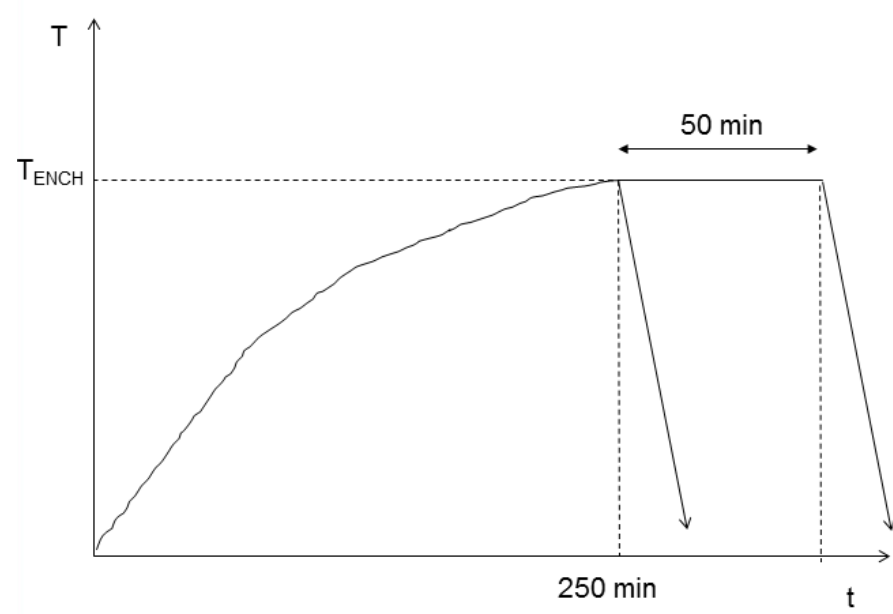

Figura 1. llustração esquemática dos tratamentos térmicos realizados.

O estudo do tamanho e da distribuição dos precipitados foi feito por microscopia eletrônica de varredura, utilizando-se o software Aztec. Foram analisadas as regiões pobres em precipitados (intradendríticas) e as regiões ricas em precipitados (interdendríticas), áreas de microssegregação. Para isso, foram selecionadas três regiões ricas em microssegregação e três regiões pobres, para cada amostra, sendo analisada uma área total de $265 \mu \mathrm{m}^{2}$ para cada região. Todas as partículas observadas foram analisadas por EDS (Espectroscopia por Dispersão de Energia) para verificar a presença de $\mathrm{Nb}$ e/ou $\mathrm{Ti}$.

\section{RESULTADOS E DISCUSSÃO}

\subsection{Caracterização Microestrutural das Amostras de Placas}

A Figura 2 apresenta as imagens obtidas por microscopia óptica para as amostras de placas, nas posições do centro e a $1 \frac{1}{4}$ da espessura, sem tratamento térmico.

Para os aços A e D, foram encontrados precipitados primários de $(\mathrm{Ti}, \mathrm{Nb})(\mathrm{N}, \mathrm{C})$ $(>1 \mu \mathrm{m})$, inclusões de $\mathrm{Mn}$ e óxidos nas duas posições da placa, centro e $1 / 4$ da 
espessura. Foram encontradas também, com o auxílio do MEV, regiões interdendríticas com precipitados aglomerados, com tamanho inferior a $1 \mu \mathrm{m}$, e precipitados alinhados, os quais são formados nos contornos de antigos grãos austeníticos $[2,4,5]$. Para o aço $\mathrm{C}$, foram encontrados precipitados primários, inclusões de $\mathrm{Mn}$ e óxidos somente na posição do centro da espessura. Regiões interdendríticas e precipitados alinhados foram encontrados nas duas posições. Com relação ao aço $B$, não foram encontrados precipitados primários e inclusões em nenhuma das duas posições, assim como regiões interdendríticas. Raramente foram observados precipitados alinhados nas duas posições da placa.

Todos os precipitados observados nas regiões interdendríticas, com tamanho superior a $100 \mathrm{~nm}$, possuíam uma morfologia cruciforme, Figura 3a. Isto foi similar para as amostras dos aços A, C e D. Precipitados com tamanho inferior a $70 \mathrm{~nm}$ apresentaram morfologia esférica, enquanto que os precipitados com tamanho entre 70 e $100 \mathrm{~nm}$, apresentaram morfologia intermediária entre esférica e cruciforme. Precipitados cubóides foram observados por MEV unicamente na posição a $1 / 4$ da espessura do aço $A$, conforme mostrado na Figura $3 b$.

A Figura 4 apresenta os gráficos da distribuição de tamanho dos precipitados presentes nas regiões interdendríticas e intradendríticas para seções retiradas do centro da espessura das placas. Os precipitados primários não foram incluídos nesta análise, uma vez que não se dissolvem durante o reaquecimento.

Observa-se que para 0 aço $B$ não foram encontradas regiões interdendríticas, somente foram encontradas regiões intradendríticas, nas quais o tamanho dos precipitados foi menor que $150 \mathrm{~nm}$. Para os outros aços, foram encontradas regiões intradendríticas e interdendríticas, sendo que, nas regiões intradendríticas, 0 tamanho dos precipitados foi menor que $200 \mathrm{~nm}$ para os aços $A$ e $C$ e para o aço D este tamanho chegou até $250 \mathrm{~nm}$. Para as regiões interdendríticas, os precipitados alcançaram um diâmetro de até $650 \mathrm{~nm}$, para os aços A e C. Como esperado, a população de precipitados foi maior nas regiões interdendríticas. Para algumas partículas menores que $50 \mathrm{~nm}$, não se detectou a presença de $\mathrm{Nb}$ e Ti, mesmo tendo morfologia similar à dos precipitados maiores. As mesmas não foram incluídas na distribuição e por essa razão o valor da frequência para os precipitados com tamanho inferior a $50 \mathrm{~nm}$ foi sombreada, sinalizando resultados abaixo da resolução do EDS. De acordo com Roy [2], a frequência de precipitados com diâmetro menor que $50 \mathrm{~nm}$ é muito maior que a dos precipitados maiores que $50 \mathrm{~nm}$ e, além disso, existe uma relação exponencial da frequência com o inverso do tamanho dos precipitados. 


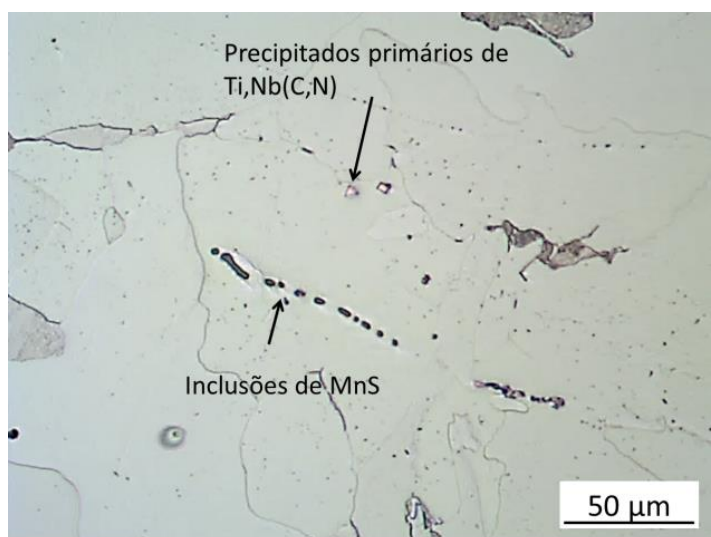

(a) Centro

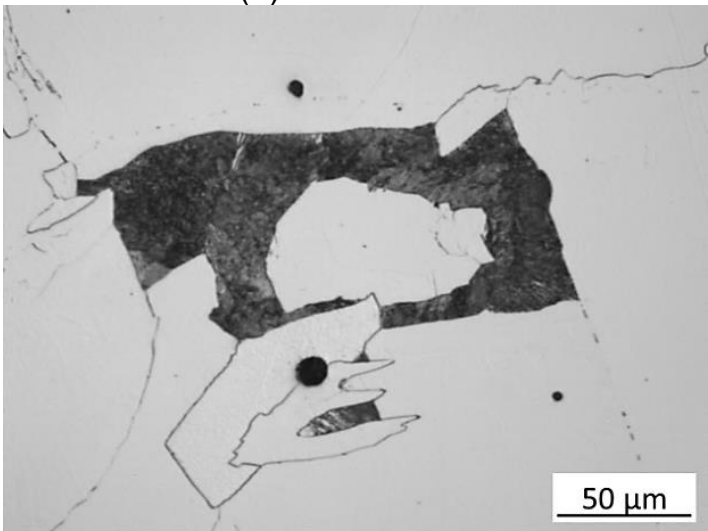

(c) Centro

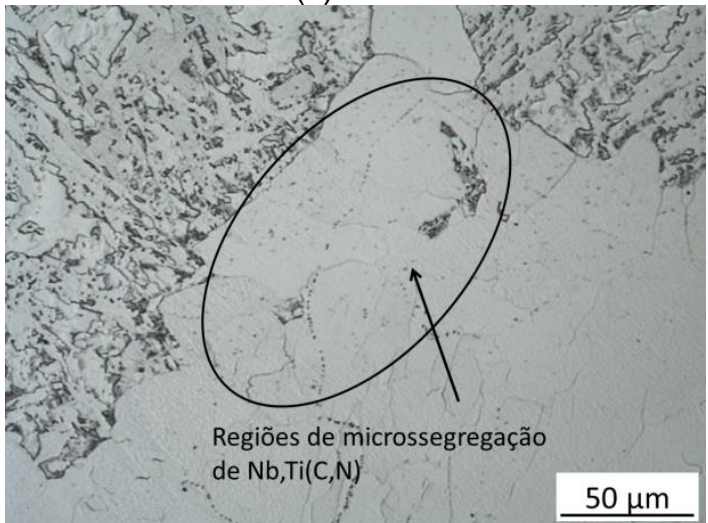

(e) Centro

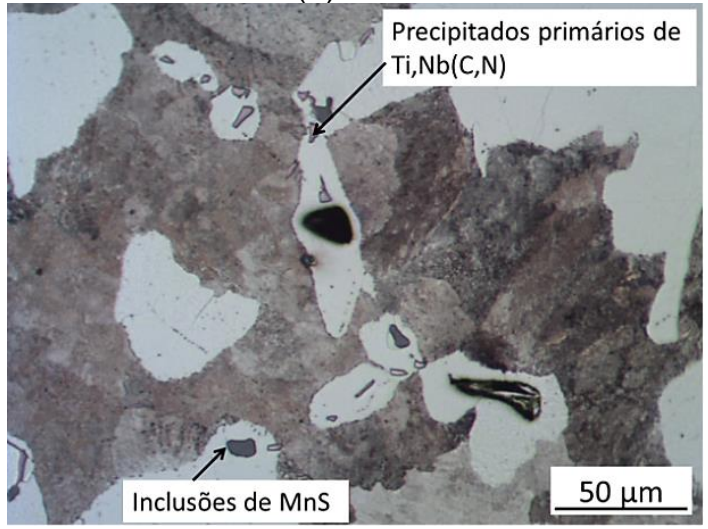

(g) Centro

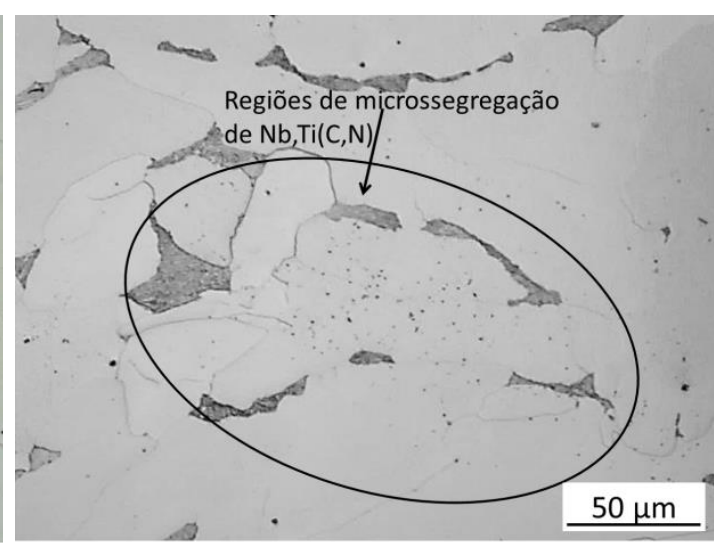

(b) $1 / 4$ da espessura

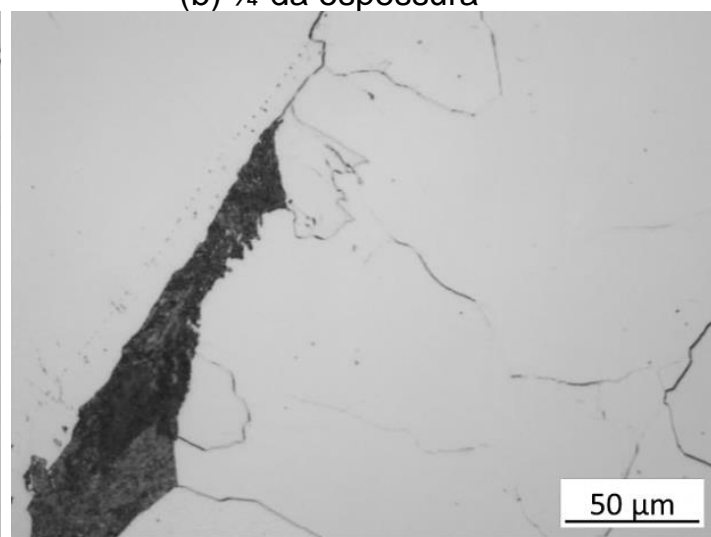

(d) $1 / 4$ da espessura

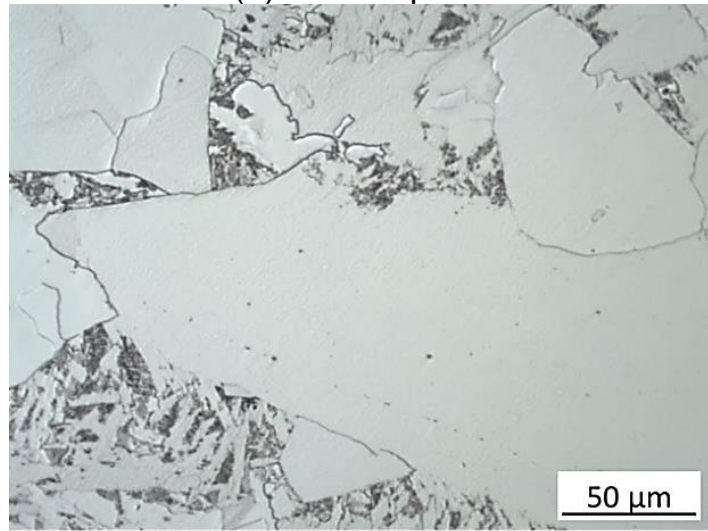

(f) $1 / 4$ da espessura

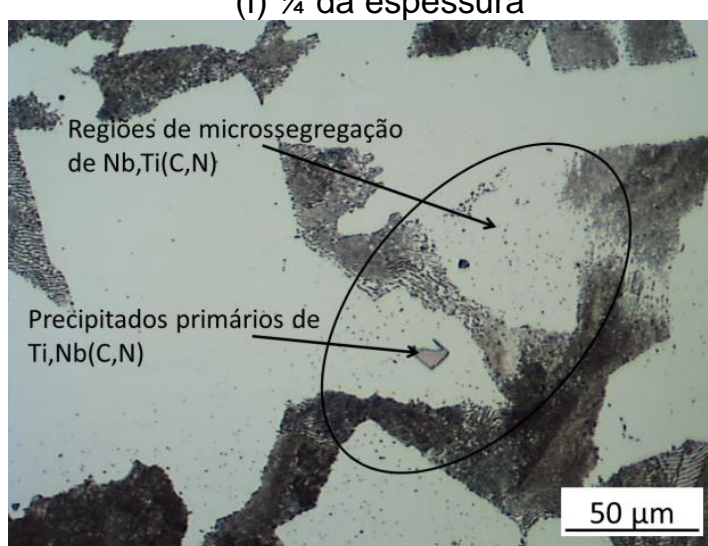

(h) $1 / 4$ da espessura

Figura 2. Imagem de microscopia óptica de seções retiradas no centro e a $1 / 4$ da espessura das amostras de placas na condição como lingotada. (a) e (b) Aço A. (c) e (d) Aço B. (e) e (f) Aço C e (g) e (h) Aço D. Ataque nital $2 \%$. 


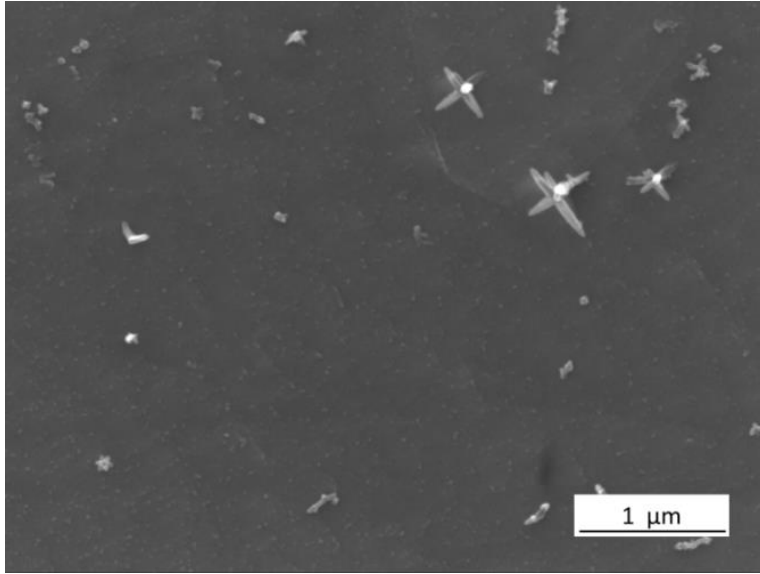

(a)

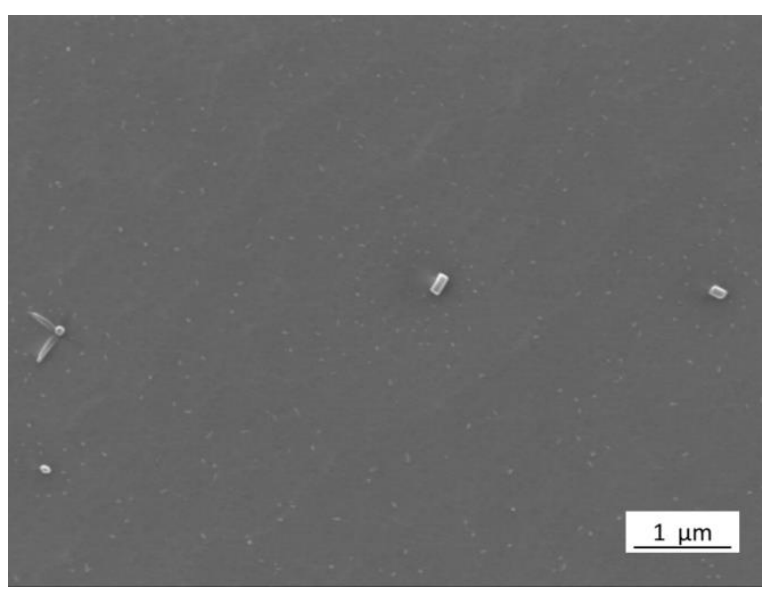

(b)

Figura 3. Imagens dos precipitados de $(\mathrm{Nb}, \mathrm{Ti})(\mathrm{C}, \mathrm{N})$, obtidas por $\mathrm{MEV}$, de seção retirada a $1 / 4 \mathrm{da}$ espessura da amostra de placa do aço A. Pode se observar a presença de precipitados cruciformes, esféricos(a) e cruciformes e cuboides(b).

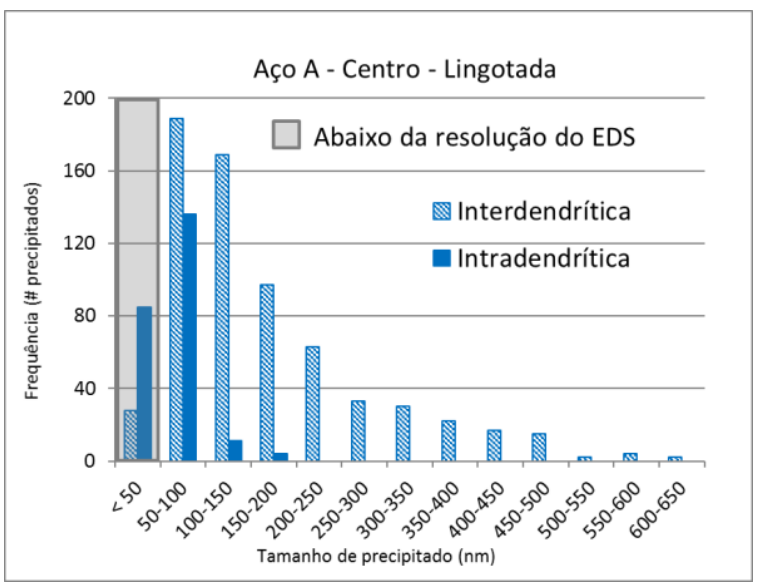

(a)

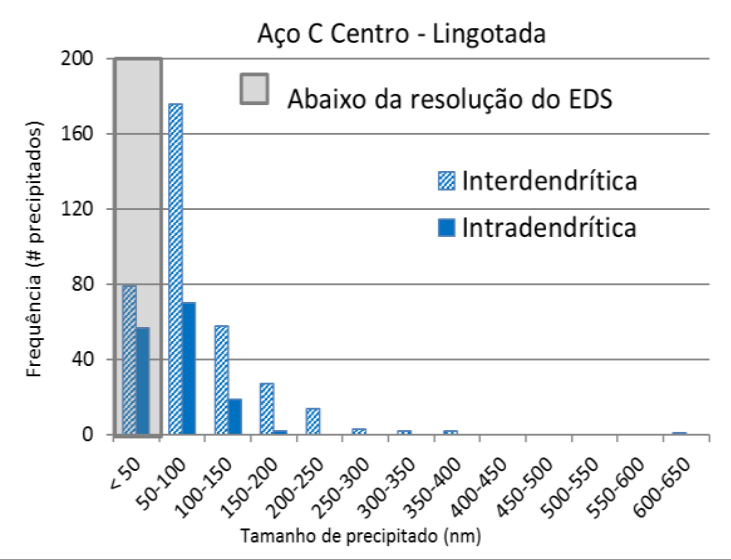

(c)

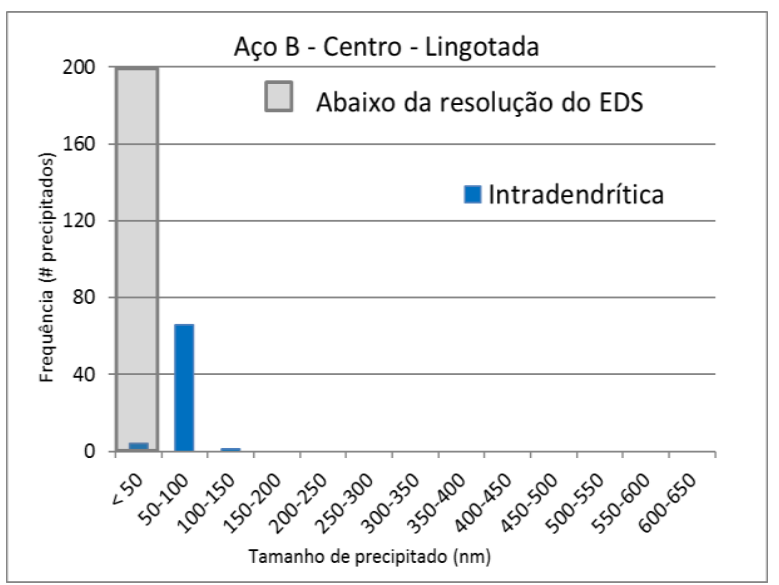

(b)

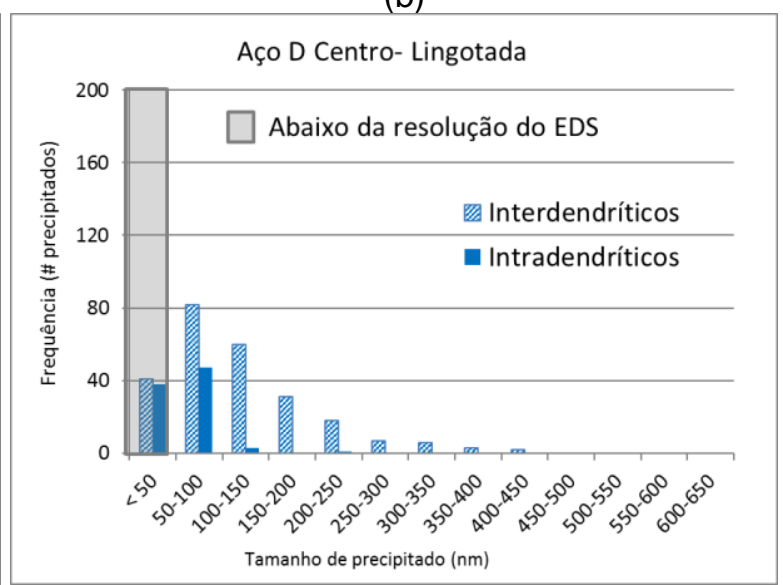

(d)

Figura 4. Distribuição do tamanho dos precipitados nas regiões interdendríticas e intradendríticas para a posição do centro da espessura das amostras como lingotadas. $O$ aço $B$ não apresentou região interdendrítica. A área total analisada para cada região foi de $265 \mu \mathrm{m}^{2}$.

\subsection{Dissolução dos Precipitados}

$\mathrm{Na}$ Figura 5 são apresentados os gráficos de distribuição de tamanho dos precipitados presentes nas regiões interdendríticas para os aços $A, C$ e $D$ e na 
região intradendrítica para o aço $B$, para subamostras retiradas da posição do centro da espessura das placas nas condições sem tratamento térmico e após encharque com tempo de 0 e 50 minutos, t0 e t50, respectivamente. Para os aços $A$ e $C$, observa-se que após $50 \mathrm{~min}$ de encharque, a maioria dos precipitados presentes nas regiões interdendríticas apresentou tamanho entre $50 \mathrm{~nm}$ e $150 \mathrm{~nm}$. No caso do aço $B$, após o tratamento de encharque, t0 e t50, a maioria dos precipitados apresentou tamanho inferior a $100 \mathrm{~nm}$. Por fim, pode-se verificar que para o aço D foram detectados precipitados com tamanho entre $350 \mathrm{~nm}$ e $400 \mathrm{~nm}$ mesmo após 50 min de encharque.

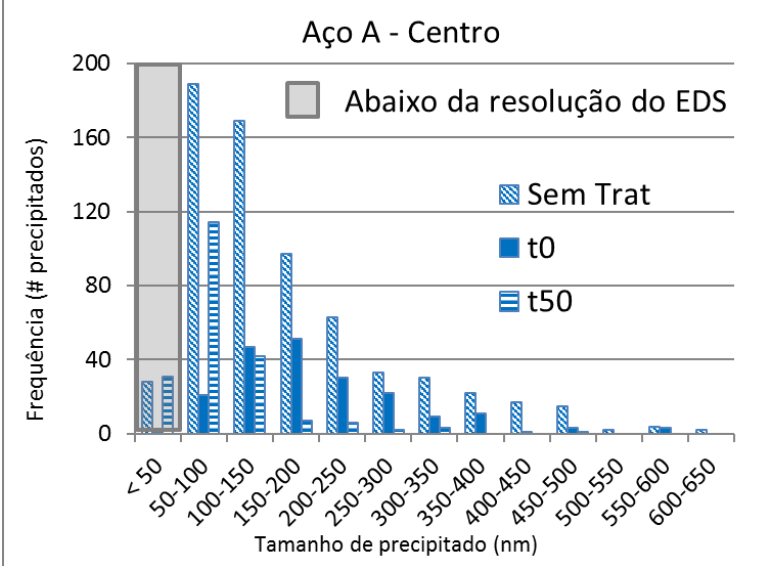

(a)

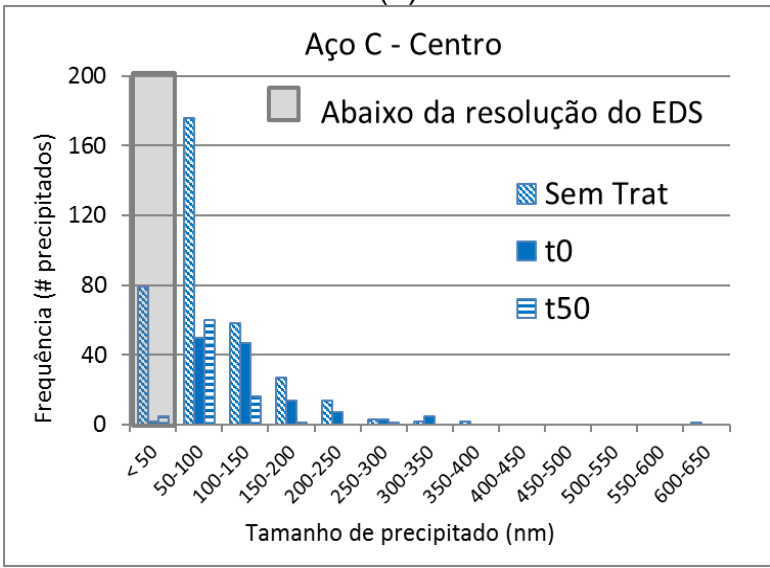

(c)

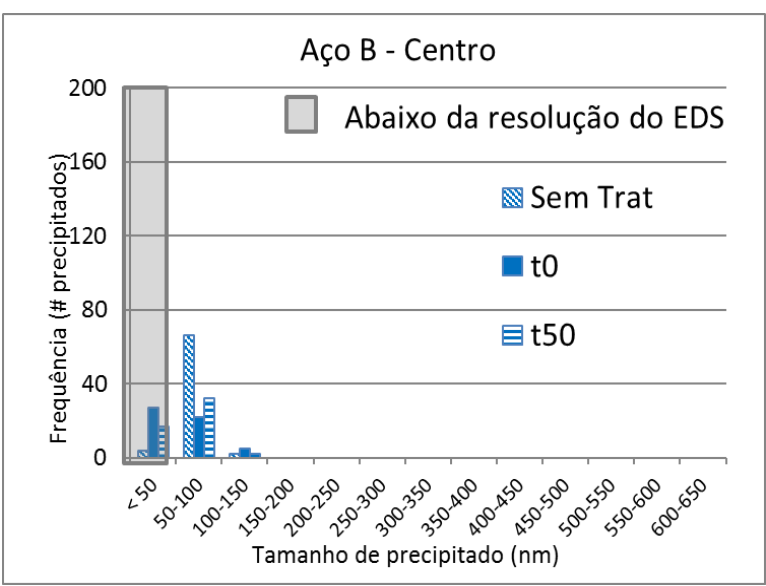

(b)

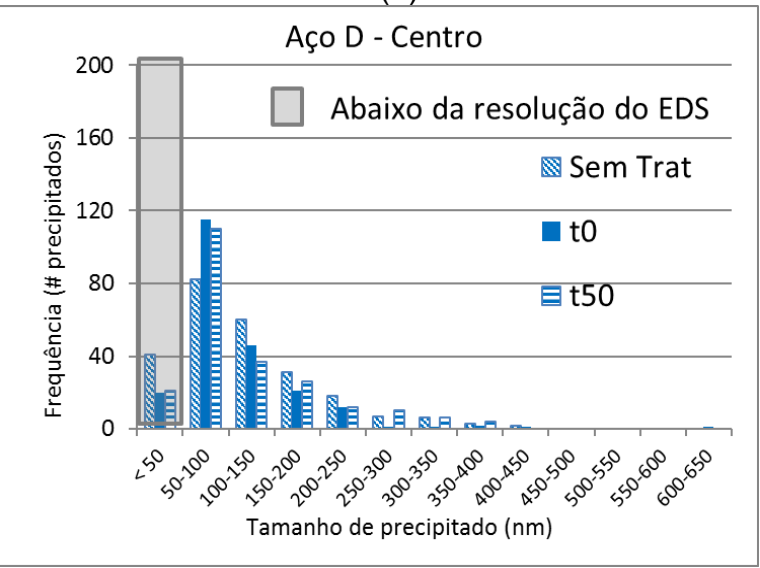

(d)

Figura 5. Distribuição de tamanho dos precipitados de $(\mathrm{Nb}, \mathrm{Ti})(\mathrm{C}, \mathrm{N})$ após diferentes tempos de dissolução para as regiões interdendríticas dos aços $A, C$ e D. Para o aço $B$ a distribuição se refere à região intradendrítica. A área total analisada para cada região foi de $265 \mu \mathrm{m}^{2}$

Os valores de fração de área dos precipitados e de diâmetro médio nas regiões interdendríticas e intradendríticas estão apresentados nas Tabelas 3 e 4.

Os resultados mostram uma maior fração de área de precipitados e um maior diâmetro nas regiões interdendríticas, o que está de acordo com Roy [2]. Para os aços $A$ e $C$, observa-se uma diminuição da fração de área dos precipitados tanto para t0 como para t50, indicando a ocorrência de dissolução com os tratamentos térmicos. Para t0, o diâmetro médio aumentou, indicando que os precipitados finos (abaixo de $100 \mathrm{~nm}$ ) dissolveram com maior facilidade, deslocando a distribuição de tamanho para a direita, ver Figura 5. Com o aumento do tempo de encharque para 50 min, o diâmetro médio dos precipitados na região rica em microssegregação diminuiu. Como a maioria dos precipitados mais finos já havia dissolvido em t0, 
conclui-se que os precipitados médios (entre $100 \mathrm{~nm}$ e $500 \mathrm{~nm}$ ) começaram a dissolver nesse intervalo. Não foi observada redução do diâmetro médio dos precipitados para os dois tempos de encharque na região intradendrítica, indicando que os precipitados se dissolveram mais facilmente nas regiões interdendríticas. Para o aço C, tratado com 50 min de encharque, as frações de área e diâmetros das regiões interdendríticas e intradendríticas foram praticamente iguais, indicando que após o tratamento já não existiam mais regiões interdendríticas. Para o aço $\mathrm{B}$, a fração de área dos precipitados e o diâmetro médio diminuíram com o tratamento térmico, não sendo possível observar diferença entre t0 e t50, comprovando que os precipitados dissolveram durante a etapa de reaquecimento, não havendo, portanto, dissolução adicional significativa com o aumento do tempo de encharque. Para o aço $\mathrm{D}$, a fração de área dos precipitados e o diâmetro médio na região interdendrítica diminuíram após o material atingir a temperatura de encharque (tempo de encharque $=0 \mathrm{~min}$ ), indicando a ocorrência de dissolução durante a etapa de reaquecimento. Por outro lado, para a região intradendrítica, a fração de área aumentou, o que pode estar associado ao coalescimento dos precipitados. Não foram observadas diferenças significativas de fração de área e de diâmetro médio de precipitados entre t0 e t50, o que é um indício de que o tempo de encharque não teve influência aparente nestes valores. Por fim, vale ressaltar que, mesmo contendo o menor teor de $\mathrm{Nb}$ dentre os aços estudados, o aço $\mathrm{A}$ foi o que apresentou a maior fração de precipitados e, de modo geral, o maior diâmetro médio, superando o aço $\mathrm{D}$, com maiores teores de $\mathrm{C}$ e $\mathrm{Nb}$ e também maior razão $\mathrm{Ti} / \mathrm{N}$. A razão para esse comportamento não foi totalmente esclarecida, mas é provável que esteja relacionada com a maior quantidade de perlita e de precipitados primários formados no aço D. A presença de perlita pode ter dificultado a detecção das partículas mais finas e a maior quantidade de precipitados primários pode ter resultado em menor quantidade de $\mathrm{Nb}$ disponível para a precipitação em temperaturas mais baixas.

Tabela 3. Fração de área dos precipitados por região, intradendrítica (intra) e interdentrítica (inter), para os quatro aços analisados $\left(\times 10^{-4}\right)$

\begin{tabular}{ccccccc}
\hline Aço & \multicolumn{2}{c}{ Sem tratamento } & \multicolumn{2}{c}{ t0 } & \multicolumn{2}{c}{ t50 } \\
\hline & Inter & Intra & Inter & Intra & Inter & Intra \\
\hline A & 266,0 & 17,4 & 97,2 & 6,3 & 24,1 & 7,6 \\
B & - & 3,4 & - & 2,9 & - & 2,6 \\
C & 45,3 & 7,8 & 25,5 & 7,7 & 6,5 & 5,3 \\
D & 49,1 & 3,4 & 41,2 & 14,8 & 42,3 & 16,1 \\
\hline
\end{tabular}

Tabela 4. Diâmetro médio $(\mathrm{nm})$ dos precipitados por região, para os quatro aços

\begin{tabular}{ccccccc}
\hline Aço & \multicolumn{2}{c}{ Sem tratamento } & \multicolumn{2}{c}{ to } & \multicolumn{2}{c}{ t50 } \\
\hline & Inter & Intra & Inter & Intra & Inter & Intra \\
\hline A & 168 & 62 & 200 & 86 & 92 & 87 \\
B & - & 68 & - & 62 & - & 62 \\
C & 102 & 64 & 124 & 86 & 81 & 78 \\
D & 122 & 59 & 107 & 85 & 112 & 86 \\
\hline
\end{tabular}

\section{CONCLUSÃO}

Para os aços A e C, com teores de C e Nb iguais a 0,087\% e 0,019\% e 0,074\% e 0,046\%, respectivamente, e razão Ti/N entre 4,2 e 6,9, observou-se dissolução total dos precipitados finos $(<100 \mathrm{~nm})$ durante o reaquecimento e dissolução apenas parcial de precipitados com tamanho entre 100 e $500 \mathrm{~nm}$ durante o encharque. Para o aço $\mathrm{B}$, com $0,038 \%$ de $\mathrm{C}, 0,032 \%$ de $\mathrm{Nb}$ e razão $\mathrm{Ti} / \mathrm{N}$ de 2,3 , os precipitados 
formados durante a solidificação do aço, com tamanho inferior a $150 \mathrm{~nm}$, foram dissolvidos durante 0 reaquecimento do material, não necessitando de tempo adicional de encharque. Com relação ao aço $D$, cujo diâmetro dos precipitados ricos em $\mathrm{Nb}$ alcançou até $650 \mathrm{~nm}$, não houve dissolução significativa durante a etapa de encharque para tempo de até $50 \mathrm{~min}$. Foi observada apenas a dissolução dos precipitados finos durante a etapa de reaquecimento. As análises realizadas para esse material indicaram a possibilidade de coalescimento dos precipitados durante a etapa de encharque. Com relação aos precipitados primários formados nos aços $A$, $\mathrm{C}$ e $\mathrm{D}$, com tamanho superior a $1 \mu \mathrm{m}$, a dissolução foi pouco significativa durante as etapas de reaquecimento e encharque.

Observou-se que, além dos teores de $\mathrm{C}$ e $\mathrm{Nb}$, a razão $\mathrm{Ti} / \mathrm{N}$ teve influência significativa e proporcional na fração de área e no tamanho dos precipitados.

Por fim, verificou-se que quanto maior a limpidez do material e menor o grau de segregação, maior foi a tendência de formação de precipitados mais finos, os quais se dissolveram mais facilmente durante o reaquecimento da placa. Em função da presença de segregação, a fração de área e o diâmetro médio dos precipitados nas regiões interdendríticas foram maiores do que nas regiões intradendríticas.

\section{Agradecimentos}

Os autores agradecem à Companhia Brasileira de Mineração e Metalurgia - CBMM pelo apoio financeiro e à Usiminas pelo apoio técnico e fornecimento de amostras. Margareth Spangler Andrade agradece ao CNPq pela bolsa concedida.

\section{REFERÊNCIAS}

1 Vervynckt S, Verbeken K, Thibaux P, Liebeherr M, Houbaert Y. Austenite Recrystallization-Precipitation Interaction in Niobium Microalloyed Steels. ISIJ International. 2009; 49 (6): pp 911-920.

2 Roy S, Patra S, Neogy S, Laik A, Choudhary SK, Chakrabarti D. Prediction of inhomogeneous distribution of microalloy precipitates in continuous-cast high strength, low-alloy steel slab. Metallurgical and Materials Transactions A. 2012; 43: pp 18451860.

3 Lee H, Park KS, Lee JH, Heo YU, Suh DW, Bhadeshia HKDH. Dissolution behavior of $\mathrm{NbC}$ during Slab Reheating. ISIJ International. 2014; 54(7): pp 1677-1681.

4 Lage MG, Costa e Silva ALV. Evaluating segregation in HSLA steels using computational thermodynamics. Journal of materials research and technology. 2015; 4(4): pp. 353-358.

5 Luo H, Karjalainen LP, Porter DA, Liimatainen HM, Zhang Y. The Influence of Ti on the Hot Ductility of $\mathrm{Nb}$-bearing Steels in Simulated Continuous Casting Process. ISIJ International. 2002; 42(3): pp. 273-282. 